\title{
Modeling rainfall infiltration through coarse and fine-grained unsaturated geomaterials
}

\author{
G. Rotisciani, A. Desideri \\ Dipartimento Ingegneria Strutturale e Geotecnica \\ Università di Roma La Sapienza, Via Eudossiana 18, 00184 Rome, Italy
}

G. Sciarra

Dipartimento Ingegneria Chimica Materiali Ambiente

Università di Roma La Sapienza, Via Eudossiana 18, 00184 Rome, Italy

F. Casini

Departamento de Ingeniería del Terreno, Cartográfica y Geofísica

Universitat Politècnica de Catalunya, C. Jordi Girona 1-3, 08034 Barcelona, Spain

\begin{abstract}
In this paper we study an imbibition test problem defined over a real two-dimensional soil domain subject to in-situ stresses and oedometric boundary conditions. Two different kinds of materials are tested, which are characterized by different pore-structures and hydro-mechanical properties. The aim is that of clarifying the behavior of real materials under real loading conditionss. The stress paths associated to rainfall infiltration processes are simulated by using the commercial code ABAQUS, endowed with an own-made subroutine developed in order to incorporate the effects of partial saturation into the tangent stiffness.
\end{abstract}

\section{INTRODUCTION}

The behavior of two partially saturated geomaterials is compared and analyzed in terms of the stress paths induced by rainfall infiltration. We distinguish between a coarse and a fine-grained material, specifying on one hand different physical and mechanical properties, on the other different hydraulic characteristics. Within this context partial saturation is expected to strongly affect the constitutive law of the overall porous medium, in terms of its elasto-plastic behavior, retention properties and the permeability of the skeleton.

The addressed problem concerns with an homogeneous layer delimited by the horizontal ground surface, through which water infiltrates. In particular the behavior of the considered unsaturated soils is discussed with respect to the showing up of wetting collapse, starting from normal consolidation, when approaching saturated conditions. The comparison between the coarse and the fine-grained soils is developed in order to underline the influence of the retention and the permeability curves on the response of the material.

This study is propedeutic for a better understanding of the behavior of slopes in condition of partial satura- tion, during rainfall events, and possibly for the identification of the mechanisms which trigger lanslides.

\section{THE POROMECHANICAL MODEL}

A continuum model is adopted for describing a porous skeleton whose pore space is assumed to be partly saturated by a wetting fluid $(w)$ and a gaseous mixture of vapor and dry air $(a)$. The wetting fluid is required to be incompressible and the effect of the partial saturation is described by introducing the degree of saturation $S_{r}$. The poromechanical constitutive model, capable for describing the behavior of partially saturated soils will be deduced extending classical thermodynamical arguments. Following Houlsby (1997) and Coussy (2010), the dissipation and consequently the Clausius-Duhem inequality is:

$$
\begin{gathered}
-\frac{1}{\rho_{a}}\left(p_{a, k}-\frac{b_{k}^{a}}{\phi_{a}}\right) M_{k}^{a}-\frac{1}{\rho_{w}}\left(p_{w, k}-\frac{b_{k}^{w}}{\phi_{w}}\right) M_{k}^{w} \\
+\sigma_{i j} \dot{\varepsilon}_{i j}+p_{a} \frac{d \phi_{a}}{d t}+p_{w} \frac{d \phi_{w}}{d t}-\frac{d \Psi_{s}}{d t} \geq 0,
\end{gathered}
$$

where $\phi_{a}=\phi S_{a}=\phi\left(1-S_{r}\right)$ and $\phi_{w}=\phi S_{r}$ are the (Lagrangian) porosities of the two saturating fluids 
and $\phi$ the total porosity; $\sigma_{i j}, p_{a}$ and $p_{w}$ are the overall stress and the pressures of the saturating phases. $M_{k}^{\pi}$ indicates the Lagrangian flow of the $\pi$ phase through the solid. In equation (1) we a-priori neglected the molecular diffusion of the vapor through the gas and treat the vapor-air mixture as an overall constituent which can only be trasported by Darcean advection through the pores; in other words no Fickian contribution to dissipation is taken into account. This assumption is well grounded when dealing with quite permeable materials, for which the characteristic time of the molecular diffusion of vapor and air is much larger than that of the advection of the whole mixture, Coussy (2010). Assuming incompressibility of the solid grains implies the Bishop effective stress tensor $\sigma_{i j}^{\prime}:=-\left(\sigma-\left(1-S_{r}\right) p_{a}+S_{r} p_{w}\right) \delta_{i j}+\operatorname{dev} \sigma_{i j}$ and the suction $s:=p_{a}-p_{w}$ to be introduced. According with the previous remarks and following an argument proposed by Coussy (2010), we assume from now on $p_{a}=0$. The dissipation can therefore be split into two contributions: one related to the skeleton and one to the wetting fluid.

Consider first of all the behavior of the solid skeleton; following Jommi (2000) and Tamagnini (2004), we adopt the Modified Cam-Clay model extended to the case of partially saturated soils. Assume the yield locus to be prescibed in terms of the Bishop effective stress components as $f_{c c}=q^{2}+M^{2} p^{\prime}\left(p^{\prime}-p_{c}^{\prime}\right)=0$, where $p^{\prime}$ is the spherical part of $\sigma_{i j}^{\prime}, q:=\sqrt{3 J_{2}}=$ $3 \sqrt{\left(I_{1}^{2} / 3-I_{2}\right)}$ is the deviator stress and $p_{c}^{\prime}$ the hardening parameter depending on the degree of saturation. As usual $M$ indicates the slope of the Critical State Line (CSL). An associated flow rule is assumed for prescribing plastic strains whose evolution is therefore given by

$$
\begin{aligned}
\dot{\varepsilon}_{v}^{p} & =\Lambda \frac{\partial f_{c c}}{\partial p^{\prime}}=\Lambda M^{2}\left(2 p^{\prime}-p_{c}^{\prime}\right), \\
\operatorname{dev} \dot{\varepsilon}_{i j}^{p} & =\Lambda \frac{\partial f_{c c}}{\partial q} \frac{\partial q}{\partial \sigma_{i j}^{\prime}}=3 \Lambda\left(\operatorname{dev} \sigma_{i j}^{\prime}\right) .
\end{aligned}
$$

Assuming the hardening internal variable to coincide with the volumetric plastic strain and the corresponding force to equal the opposite of $p_{c}^{\prime}$, a state equation, linking $p_{c}^{\prime}$ with $\varepsilon_{v}^{p}$, need to be formulated. Following Tamagnini (2004) the time evolution of $p_{c}^{\prime}$ is defined in terms of a double-hardening mechanism: $\dot{p}_{c}^{\prime}=\dot{p}_{c(\text { sat })}^{\prime}+\dot{p}_{c(\text { unsat })}^{\prime}$, with

$\dot{p}_{c(\text { sat })}^{\prime}=\frac{v p_{c}^{\prime}}{\lambda-\kappa} \dot{\varepsilon}_{v}^{p}, \quad \dot{p}_{c(\text { unsat })}^{\prime}=-b p_{c}^{\prime} \dot{S}_{r}$

Here $v=1+e=1 /(1-n)$ is the specific volume, given in terms of the void ratio $e$ or the Eulerian porosity $n ; \kappa$ and $\lambda$ are the slopes of the unloadingreloading line and the Normal Consolidation Line (NCL), both in a semi-logarithmic picture.
The equation for the plastic multiplier reads as:

$$
\begin{aligned}
& \Lambda=\frac{1}{H}\left[2 M^{2}\left(p^{\prime}-\frac{1}{2} p_{c}^{\prime}\right) \dot{p}^{\prime}+\left(\operatorname{dev} \sigma_{i j}^{\prime}\right) \operatorname{dev} \dot{\sigma}_{i j}^{\prime}\right. \\
& \left.-M^{2} p^{\prime} \frac{\partial p_{c}^{\prime}}{\partial S_{r}} \dot{S}_{r}\right], H=2 M^{4} p^{\prime}\left(p^{\prime}-\frac{1}{2} p_{c}^{\prime}\right) \frac{\partial p_{c}^{\prime}}{\partial \epsilon^{p}} .
\end{aligned}
$$

The material exhibits therefore a hardening (softening) behavior when $p^{\prime}>p_{c}^{\prime} / 2\left(p^{\prime}<p_{c}^{\prime} / 2\right)$, which corresponds to $H>0(H<0)$. It is worth to notice that non-vanishing $\Lambda$ can also be obtained when $\dot{S}_{r}>0$ (wetting), keeping constant the overall stress. This condition models the well-known collapse by wetting.

Consider finally the wetting fluid, merging Darcy's law with the wetting fluid mass balance, the governing equation for the saturation degree can be obtained:

$\frac{d}{d t}\left(\phi S_{r}\right)=-\left[k_{\text {sat }} k\left(S_{r}\right)\left(s_{, k}+\frac{b_{k}^{w}}{\phi_{w}}\right)\right]_{, k}$

which is known as Richards' equation.

\section{IMBIBITION OF A SOIL LAYER IN OEDOMETRIC CONDITIONS}

In this section we present an imbibition test problem defined for a real two-dimensional soil domain, subject to in-situ stresses and oedometric boundary conditions. Two different kinds of materials are tested, which are characterized by different pore-structures, say values of the initial void ratio, and different hydromechanical properties. The aim is that of clarifying the behavior of real materials under real loadings.

In the following subsections the stress paths are drawn in terms of the mean effective stress and the deviator stress at different depths. It is worth to notice that two different counterbalancing mechanisms will characterize the stress path followed during imbibition: (i) an increase in the unit weight of the soil, induced by saturation, which forces the total stress acting on the soil to increase; (ii) a decrease of the effective stress due to the decrease of suction.

\subsection{MATERIAL PROPERTIES}

The considered materials are a clayey silt and a volcanic ash, say the Jossigny silt and the Cervinara ash, according with the sites (east of Paris, France, and south on Naples, Italy), where they have been taken. They significantly differ in the physical characteristics as well as in the hydro-mechanical properties; in particular the initial void ratio, the water retention curve, the permeability and the compressibility. Furthermore the Cervinara ash is characterized by a low value of the unit weight of the solid particles, $\gamma_{s}$, and a low in situ degree of saturation, see e.g Picarelli et al. (2006). This will imply the increment of the overall weight to play a fundamental role in the increase of the total stress, during an imbibition process. 


\subsubsection{CERVINARA ASH}

The volcanic ash from Cervinara is silty sand with a non-plastic fine-grained component, generally less than $30 \%$, constituted by very poor ordered minerals (sanidine and pyroxenes) see Olivares and Picarelli (2003) and Picarelli et al. (2006).

The parameters of the Van Genuchten Water Retention Curve (WRC), see Fig.1, $S_{r}=S_{w, r}+(1-$ $\left.S_{w, r}\right) /\left[1+(\alpha s)^{n}\right]^{m}$, where $S_{w, r}$ is the residual saturation degree, have been calibrated with the experimental results obtained under suction controlled conditions and reported in Picarelli et al. (2006).

Here the unsaturated hydraulic permeability is fitted with the model $k\left(S_{r}\right)=\sqrt{S_{r}}\left[1-\left(1-S_{r}^{\delta}\right)^{\beta}\right]^{n}$.

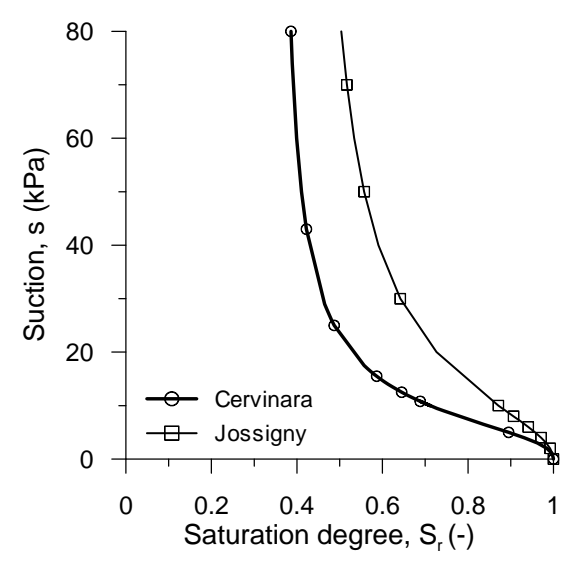

Figure 1: Water retention curves in the wetting path of the two materials.

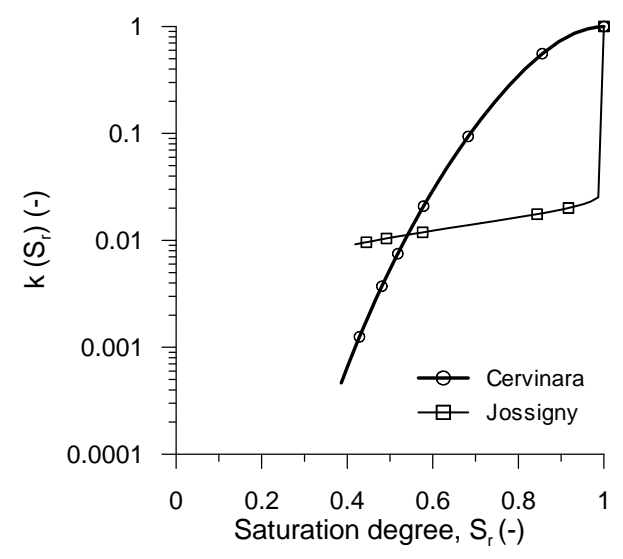

Figure 2: Relative hydraulic permeabilities $k / k_{\text {sat }}$ as a function of the saturation degree of the two materials.

The parameters $\delta, \beta$ and $n$ have been calibrated back analysing the equalisation stage of different triaxial tests related to different values of suction, looking in particular at the time evolution of the variation of the water content. In Fig. 3 a comparison between the laboratory data and the model prediction is reported in terms of the time variations of the water content. It is worth to notice that the compressibility parameters have been calibrated following the procedure reported in Casini (2012), for oedometric conditions, and extended to triaxial conditions in Casini et al. (2013). In particular the slope of the NCL and that of the

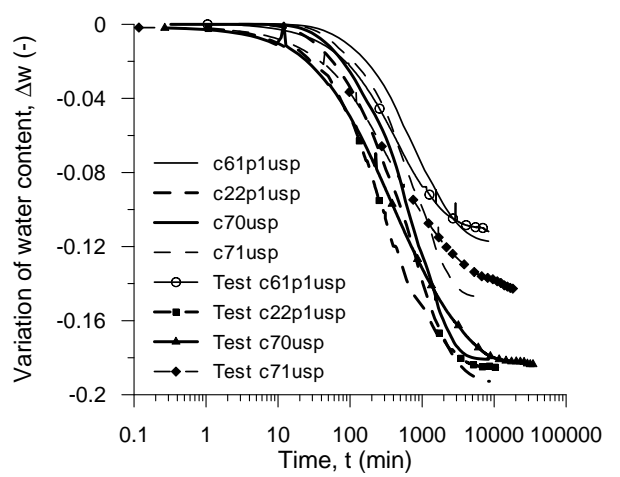

Figure 3: Comparison between numerical predictions and results of compression triaxial tests in terms of suction equalization curves: c61p1usp at $s=44 \mathrm{kPa}$ and $p=5.8 \mathrm{kPa}$, c22p1usp at $s=44 k \mathrm{~Pa}$ and $p=37 \mathrm{kPa}$, c70usp at $s=74 k \mathrm{~Pa}$ and $p=37$ $k \mathrm{~Pa}, \mathrm{c} 71 \mathrm{usp}$ at $s=74 \mathrm{kPa}$ and $p=68 \mathrm{kPa}$.

unloading-reloading line in the plane $v-\ln p^{\prime}$, say $\lambda$ and $\kappa$, are calibrated with the results of the isotropic compression tests, in saturated conditions, see Fig.4. On the other hand, the parameters $b$, which describes how the NCL translates because of partial saturation, is calibrated by the results of the isotropic compression test with suction $s=40 \mathrm{kPa}$, see Fig.4, reported in Picarelli et al. (2006).

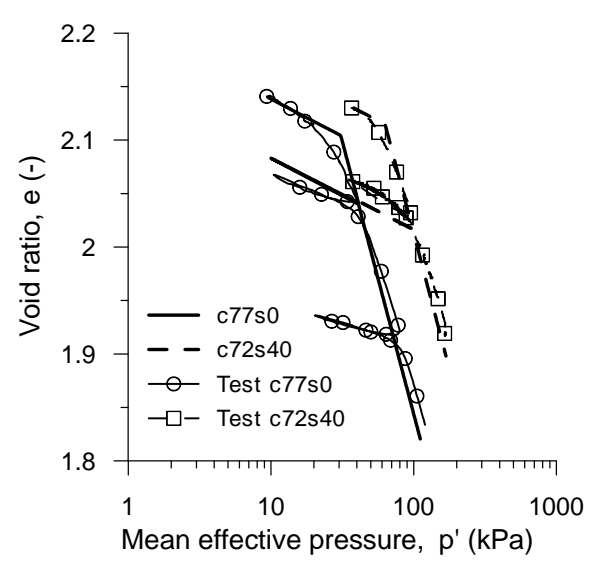

Figure 4: Comparison between numerical predictions and results of isotropic compression tests carried out on saturated (c77s0) and unsaturated (c72s40) undisturbed specimens.

\subsubsection{JOSSIGNY SILT}

The Jossigny silt has been studied in saturated and unsaturated conditions by several authors, see e.g. Casini (2012). It is a low plasticity silt with $25 \%$ of clay retrieved by an alluvial deposit located at Jossigny, east of Paris, France. Clay minerals determined by X-ray diffractometry are illite, kaolinite and interstratified illite-smectite.

The parameters of the model have been calibrated at the light of the experimental results under saturated and unsaturated condition reported in D'Onza et al. (2011) and Casini et al. (2012). The parameters of the Van Genuchten type WRC are characterized best fitting the wetting path under suction controlled conditions, with an average void ratio $e=0.82$, see Fig.1, 
whilst the relative permeability curve is the one provided by Muñoz et al. (2008), see Fig.2.

The mechanical parameters $\lambda, \kappa$ and $b$ have been calibrated considering the compression stage, under suction controlled conditions, in an oedometer apparatus. The comparison between the model prediction and the data is reported in Fig.5. The axial loading

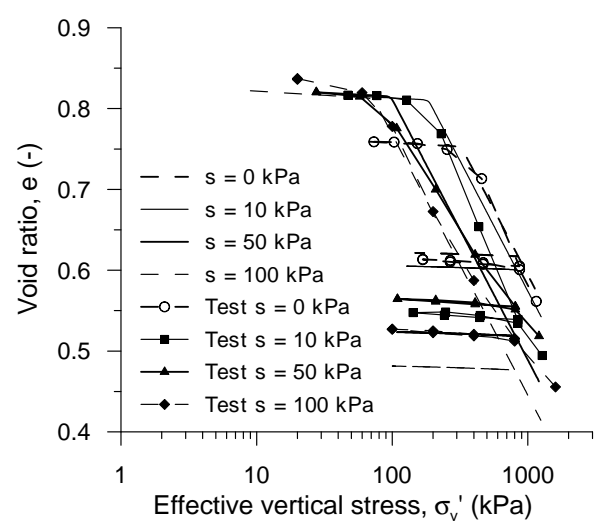

Figure 5: Comparison between numerical predictions and results of suction-controlled oedometric tests.

stage of the triaxial tests under unsaturated condition has been used to calibrate the slope of the CSL in the $\left(p^{\prime}, q\right)$ plane, say $M$.

The hydro-mechanical parameters of both materials are summarized in Table 1 and Table 2.

Table 1: Hydraulic parameters for the two materials.

\begin{tabular}{cl|cc}
\hline & & Cervinara & Jossigny \\
\hline & $\alpha\left(k \mathrm{~Pa}^{-1}\right)$ & 0.13 & 0.08 \\
& $m$ & 0.57 & 0.49 \\
WRC & $n$ & 2.32 & 1.96 \\
& $S_{w, r}$ & 0.36 & 0.41 \\
\hline \multirow{4}{*}{$\mathrm{k}$} & $k_{\text {sat }}(m / s)$ & $1.4410^{-6}$ & $3.6710^{-7}$ \\
& $\delta$ & 6 & 0.138 \\
& $\beta$ & 2.5 & $210^{-4}$ \\
& $n$ & 1.5 & 0.55 \\
\hline
\end{tabular}

Table 2: Mechanical parameters for the two materials.

\begin{tabular}{c|cccccc}
\hline & $\lambda$ & $\kappa$ & $M$ & $\nu$ & $b$ & $\begin{array}{c}\gamma_{s} \\
\left(k N / m^{3}\right)\end{array}$ \\
\hline Cervinara & 0.22 & 0.03 & 1.45 & 0.25 & 1.3 & 25.6 \\
Jossigny & 0.14 & 0.004 & 1.2 & 0.3 & 1.97 & 26.4 \\
\hline
\end{tabular}

\subsection{NUMERICAL RESULTS}

The effects induced by rainfall infiltration in an homogeneous unsaturated soil are analyzed by using plane strain numerical simulations. The finite element mesh adopted in this study is $2 \times 10 \mathrm{~m}^{2}$ and consists of 8 noded quadrilateral elements. The nodes at the lower boundary are constrained by hinges whilst those along the lateral sides can only move vertically.

In the geostatic conditions, the vertical total stress $\sigma_{v}$ increases almost linearly with depth. The porewater pressure profile is assumed hydrostatic and the groundwater table is located initially at the lower boundary. The effective horizontal stresses are expressed as a function of $\sigma_{v}^{\prime}$ through the earth pressure coefficient $K_{0}$, see Federico et al. (2009).

Starting from the initial conditions, the atmospheric pressure is prescribed at the upper boundary (surface ponding) and the water is prevented to flow out through the bottom and the lateral sides of the domain. The rainfall event is distributed over a time period longer than that of the saturation process, which means that the intensity of the rainfall is greater than the infiltration capacity of the soil.

The time evolutions of the $S_{r}$ profiles are shown in Fig.6. In both simulations, during the infiltration process a wetting front can be detected which moves downwards with a velocity depending on the hydraulic properties of the soil. The front advances more quickly in the pyroclastic soil than in the Jossigny silt, according to the smooth profile of the unsaturated permeability of volcanic ashes with suction. In the silt layer, the soil permeability, on the other hand, drops sharply for very low suction levels. Because of the difference in the permeabilities the wetting front, which propagates through the silt layer looks more steep than that moving through the pyroclastic soil, in the neighborhood of $S_{r}=1$. This means that above the front almost saturation conditions are achieved in the Jossigny silt, conversely a rather diffuse variation of $S_{r}$ can be seen in the pyroclastic soil.

In Figs.7-9 the time evolution of the pore-water pressure and the increments of the total and effective vertical and horizontal stress are shown. The results refer to two finite elements located at depths of 2 and $8 \mathrm{~m}$ from the top of the soil. Here, the increments in vertical and horizontal stress are calculated with reference to the geostatic values.

The time evolution of the pore-water pressure is shown in Fig.7. For both shallow and deep elements, the pore-water pressure increases and vanishes when the wetting front reaches the element itself. Then the pressure keeps a constant value equal to zero for a time interval, during which the wetting front moves out of the element and reaches the bottom of the domain. At this moment, the pore-water pressure starts to rise up again attaining its hydrostatic stationary value. Comparing the responses given by the two materials, it can be noticed that the saturation process is shorter in the pyroclastic than in the fine grained soil. The abrupt variation in the permeability profile of the silt is responsible of the plateau in the behavior of the pore-water pressure. On the other hand, a more smooth variation of the permeability, as in the case of coarse soils, implies the pore-water pressure to smoothly catch the atmospheric reference value.

Fig. $8 a$ illustrates the time evolution of the total vertical stress increment, $\Delta \sigma_{v}$. As the water infiltrates into the soil, $\Delta \sigma_{v}$ increases with quite constant rate until the saturation conditions are attained. After reaching saturation, the total vertical stress remains 

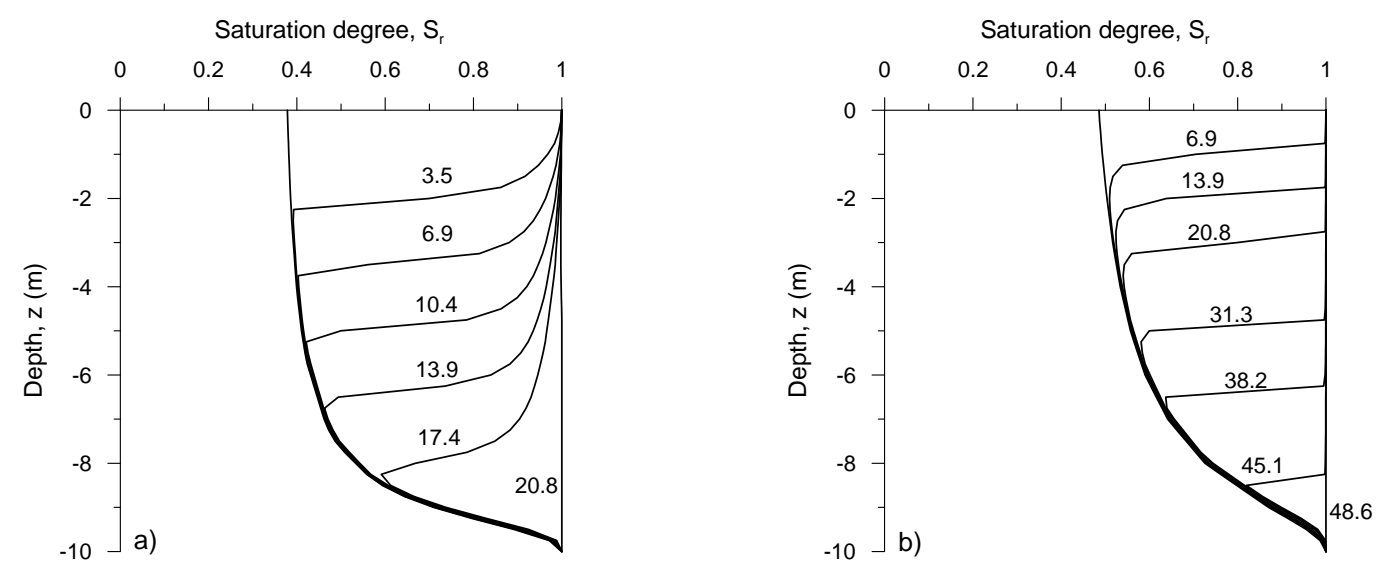

Figure 6: Isochrones (time unit: days) of the saturation degree during water infiltration tests through: (a) the Cervinara soil; (b) the Jossigny soil.

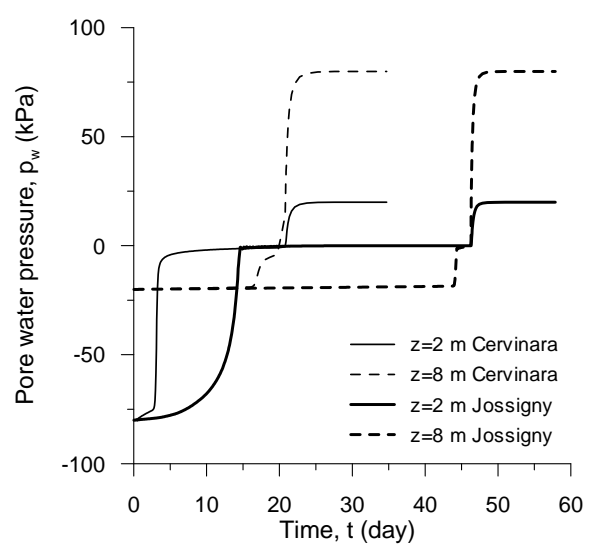

Figure 7: Time evolution at 2 and $8 m$ of the pore-water pressure.

constant. Comparing the responses of the two materials, it can be observed that at the same depth the stationary value of $\Delta \sigma_{v}$ in the volcanic ashes is larger than that of the Jossigny silt. As a matter of fact, the pyroclastic soil has an higher porosity than the silt and, consequently, it can keep a larger amount of water. This condition significantly modifies the bulk forces exerted on the solid skeleton and consequently the increment of the total vertical stress. The changes in time of the effective vertical stress increment, $\Delta \sigma_{v}^{\prime}$, are shown in Fig.8b. In this first part of the evolution process, the profile of $\Delta \sigma_{v}^{\prime}$ corresponds exactly to that of $\Delta \sigma_{v}$. Moreover when the front passes through the element, the effective vertical stress decreases and remains constant until the front reaches the bottom of the domain. At this moment, $\Delta \sigma_{v}^{\prime}$ starts to decrease again reaching the stationary value.

The time evolution of the total horizontal stress increment $\Delta \sigma_{h}$ is shown in Fig.9a. The increment of $\Delta \sigma_{h}$ is initially due to the increment of the weight and to the oedometric conditions. Afterwards, when the wetting front reaches the shallow or the deep element, the increase of $\Delta \sigma_{h}$ is mainly due to the positive variation of the pore-water pressure. The time evolution of the effective horizontal stress increment, $\Delta \sigma_{h}^{\prime}$, is similar to that of $\Delta \sigma_{v}^{\prime}$, Fig. $9 b$.

The stress-paths in the $\left(p^{\prime}, q\right)$ plane, shown in Figs.10-11, refer to four finite elements in the Cer-
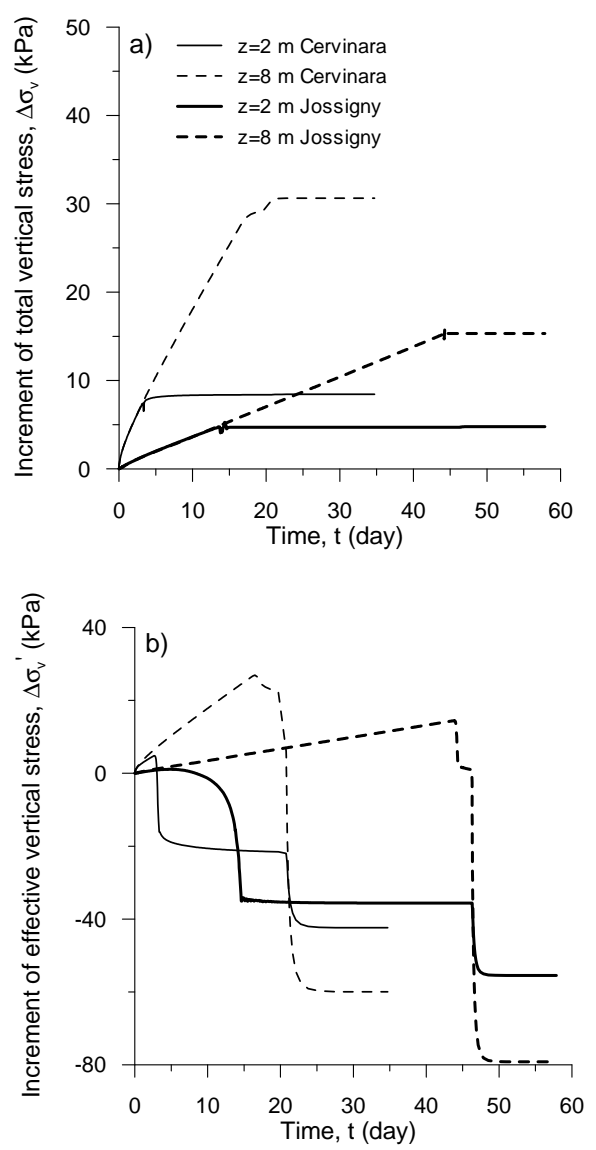

Figure 8: Time evolution at 2 and $8 \mathrm{~m}$ of: (a) increment of total vertical stress, (b) increment of effective vertical stress.

vinara and Jossigny soils, at increasing depths. The evolution of the stress state related to the rising of the ground water surface is not reported in the figures. The initial stress states, at different depths, align along the $K_{0}$-line. In the first part of the imbibition process, the increment of the bulk forces implies an increment of the mean effective pressure, as well as, of the deviator stress. The stress paths follow the $K_{0}$-line and the increment of the stress invariants is more pronounced in the deep elements of the pyroclastic soil, because of its physical properties (higher porosity) and its initial conditions (smaller degree of saturation). When the wetting front reaches the considered finite element, the saturation degree starts to increase and the stress paths change abruptly direction. During the saturation 

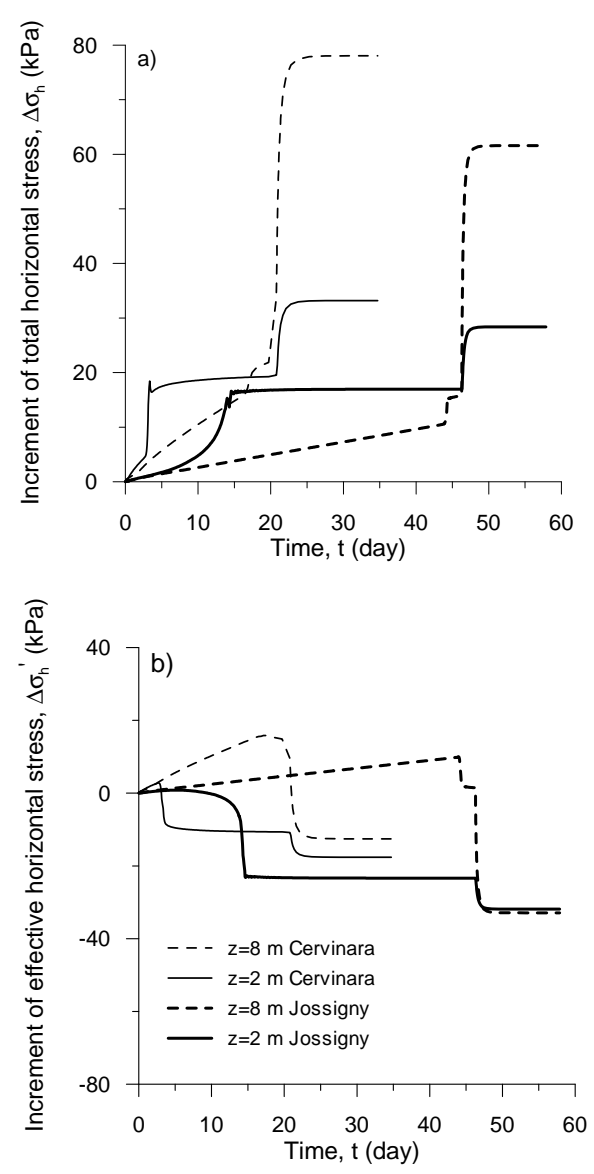

Figure 9: Time evolution at 2 and $8 m$ of: (a) increment of total horizontal stress, (b) increment of effective horizontal stress.

process not only the mean effective stress decreases but also the deviator stress, which is a consequence of the imposed oedometric conditions. This reduction in the intensity of both invariants is accompanied initially by swelling, which is more evident in the Cervinara soil, and then by volumetric collapse in the finite elements which are closer to the upper boundary of the layer. On the other hand no swelling deformations are observed in the deep elements. We underline that the difference in the swelling behavior between the two materials is due to their different elastic stiffnesses.

\section{CONCLUSIONS}

In this paper the behavior of two partially saturated soil layers during rainfall water infiltration is numerically investigated, discussing the effects of the hydromechanical coupling on water saturation profiles and stress paths.

Concerning the hydraulic aspects of the phenomenon the hydro-mechanical coupling shortens the time needed for attaining saturation conditions, in the occurrence of volumetric collapse. Apparently the response of the fluid also depends on the initial and boundary conditions as well as on the hydraulic properties of the soil. On the other hand the same hydromechanical coupling affects the mechanical behavior of the porous material because of the increase of the gravity loading during wetting, possibly enhancing
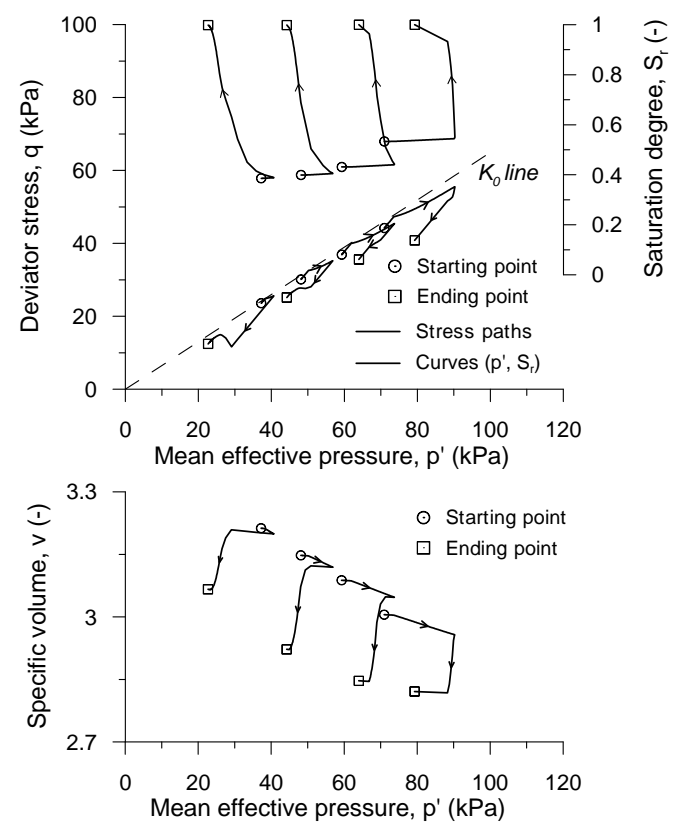

Figure 10: Stress-path and volumetric behavior of the Cervinara soil for increasing depth (left to right: $2,4,6,8 \mathrm{~m}$ ).

volumetric collapse of the soil.

Further developments will be devoted to extend our results to the case of non-horizontal ground surface with the aim of simulating the triggering conditions of shallow landslides induced by rainfall events.

\section{REFERENCES}

Casini, F. (2012) Deformation induced by wetting: a simple model. Canadian Geotechnical Journal 49, 954-960.

Casini, F., Vaunat, J., Romero, E., Desideri, A. (2012) Consequences on water retention properties of double-porosity features in a compacted silt. Acta Geotechnica 7, 139-150.

Casini, F., Serri, V., Springman, S.M. (2013) Hydromechanical behaviour of a silty sand from a steep slope triggered by artificial rainfall: from unsaturated to saturated conditions. Canadian Geotechnical Journal 50(1), 28-40.
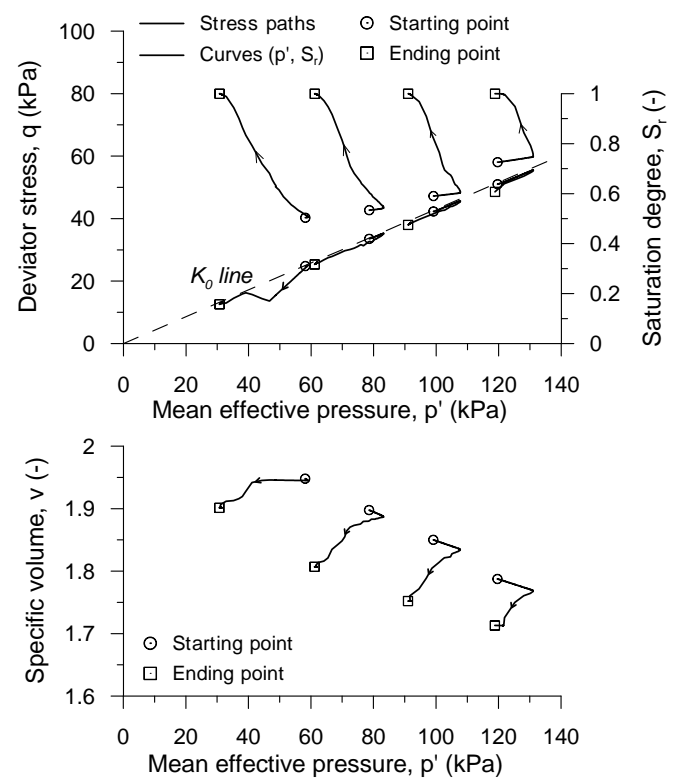

Figure 11: Stress-path and volumetric behavior of the Jossigny soil for increasing depth (left to right: $2,4,6,8 \mathrm{~m}$ ). 
Coussy, O. (2010) Mechanics and Physics of Porous Solids. John Wiley and Sons.

D’Onza, F., Gallipoli, D., Wheeler, S.J., Casini, F., Vaunat, J., Khalili, N., Laloui, L., Mancuso, C., Masin, D., Nuth, M., Pereira, J.M., Vassallo, R. (2011) Benchmarking different approaches to constitutive modelling of unsaturated soils. Géotechnique 61(4), 283-302.

Federico, A., Elia, G., Murianni, A. (2009) The at-rest pressure coefficient prediction using simple elasto-plastic constitutive models. Computers and Geotechnics 36, 187-198.

Houlsby, G.T. (1997) The work input to an unsaturated granular material. Géotechnique 47(1), 193-196.

Jommi, C. (2000) Remarks on the constitutive modelling of unsaturated soils. In: Experimental Evidence and Theoretical Approaches in Unsaturated Soils, Trento, Balkema.

Muñoz, J.J., De Gennaro, V., Delaure, E. (2010) Experimental determination of unsaturated hydraulic conductivity in compacted silt. In Unsaturated Soils, Durham, CRC.

Olivares, L. \& Picarelli, L. (2003) Shallow flowslides triggered by intense rainfalls on natural slopes covered by loose unsaturated pyroclastic soils. Géotechnique 53(2), 283-287.

Picarelli, L., Evangelista, A., Rolandi, G., Paone, A., Nicotera, M.V., Olivares, L., Scotto di Santolo, A., Lampitiello, S. \& Rolandi M. (2006). Mechanical properties of pyroclastic soils in Campania Region. In 2nd Int. Work. on Characterisation and Engineering Properties of Natural Soils, Singapore.

Tamagnini, R. (2004) An extended Cam-Clay model for unsaturated soils with hydraulic hysteresis. Géotechnique 54(3), 223-228. 